\title{
Mechanical properties and rheology of polyalkenoate cements using various low-cost fillers
}

Diego A. Acosta - Gary P. Funkhouser •

Brian P. Grady

Published online: 26 June 2007

(C) Springer Science+Business Media, LLC 2007

Erratum to: J Mater Sci (2007)

DOI: 10.1007/s10853-006-0357-4

The Publisher apologizes for a misprint that appeared on the Journal of Materials Science webpage for
"Mechanical properties and rheology of polyalkenoate cements using various low-cost fillers" by Diego A. Acosta, Gary P. Funkhouser and Brian P. Grady. The last author's name was spelled incorrectly.

The online version of the original article can be found under doi: 10.1007/s10853-006-0357-4

D. A. Acosta · B. P. Grady ( $\square)$

School of Chemical, Biological and Materials Engineering,

University of Oklahoma, 100 East Boyd, Norman,

OK 73019-0628, USA

e-mail: bpgrady@ou.edu

G. P. Funkhouser

Halliburton, Duncan, OK 73536, USA 